\title{
Analysis of the Factors Limiting the Performance of Small-to-Medium Scale Sawmills in the Copperbelt of Zambia
}

\author{
Mary Mandiringana, ${ }^{\mathrm{a}}$ Mutinta Matakala, ${ }^{\mathrm{b}}$ Ngoy Patrick Mwanabute, ${ }^{\mathrm{c}}$ Justine Ngoma, ${ }^{\mathrm{d}}$ \\ and Elisha Ncube ${ }^{\mathrm{d}, *}$
}

\begin{abstract}
Small-to-medium scale softwood sawmills in the Copperbelt of Zambia are operating below $50 \%$ capacity. The timber supply is uncertain as demand continues to increase in tandem with economic activities and population growth. This study identified the financial, i.e., access to finance and operating costs, and non-financial, i.e., raw material, transport, skilled labor, and sawn timber recovery, as the limiting factors affecting performance. The authors benchmarked various financial ratios, i.e., gross profit margin, net profit margin, return on investment, return on capital employed, and working capital turnover, of the small-scale sawmills compiled from survey data with the average industry ratios. Raw material is the most limiting factor affecting profitability/success of small-scale sawmills. A Cobb-Douglas model demonstrated that sawn timber recovery depends on operator skills, particularly in non-automatic machinery, which are common. Strategies currently employed are value addition, multiple sourcing, equipment acquisition and modernization, and labor cost reduction. Measures proposed to enhance profitability are credit guarantee schemes, collaboration, tax reduction, lesser-used timber utilization, and timber auction floor.
\end{abstract}

DOI: 10.15376/biores.17.1.369-383

Keywords: Limiting factors; Sawn timber recovery; Small-to-medium scale sawmills; Industry benchmarks; Timber supply and demand; Operator skills

Contact information: a: UNICAF University, Plot 20842, Off Alick Nkhata Road, Lusaka Zambia; b: Zambia Forestry and Forest Industries Corporation PLC, Ndola Head Office, P. O. Box 71566, Ndola Zambia; c: School of Natural Sciences and Mathematics, Department of Mathematics, Copperbelt University, P. O. Box 21692, Jambo drive, Riverside, Kitwe Zambia; d: School of Natural Resources, Department of Biomaterials Science and Technology, Copperbelt University, P. O. Box 21692, Jambo Dr., Riverside, Kitwe Zambia; *Corresponding author: enncube@yahoo.comor elisha.ncube@cbu.ac.zm

\section{INTRODUCTION}

Zambia is endowed with natural resources to the extent of 74.339 million hectares of which 45.94 million hectares are indigenous forests and woodlands (Makumba 2002; Siampale et al. 2020). Forest plantations cover approximately 75000 hectares or $0.1 \%$ of the total land area (ZFAP 1998), from which the Zambian Forest Department controls a total of 20000 hectares or $27 \%$ of the local forest plantations spread across the country (ZFAP 1998; ZAFFICO 2004).

Fifty thousand hectares of pine and eucalypt commercial plantations, established to augment supplies from indigenous forests, were parceled out to Zambia Forestry and Forest Industries Corporation (ZAFFICO) in 1982 by the Industrial Plantations Division of the 
Forestry Department. However, between 1984 and 2004 ZAFFICO did not replant any trees and only resumed doing so in the 2004 to 2008 period albeit at 63\%, i.e. 550 hectares below the expected 1800 hectares (ZAFFICO 2008; Chivuno 2010). The cumulative shortfall culminated in allowable annual cut dropping from 392,700 $\mathrm{m}^{3}$ in 2007 to 228,268 $\mathrm{m}^{3}$ in 2011 (CCPC 2016). On the other hand, the number of sawmills increased from 100 in 2008, 585 sawmills in 2013 (CCPC 2016), and to over 1000 sawmills by 2020 (ZAFFICO 2020). Sadly, in 2013 the 585 sawmills demand for softwood had swirled to $700,800 \mathrm{~m}^{3}$, and ZAFFICO could only meet $53.9 \%$ of it. The deficit obviously escalated over time and is expected to have almost doubled by 2020 .

The supply problem is compounded by local consumers whose preference for $5 \mathrm{~m}$ timber lengths contributes to $20 \%$ of merchantable roundwood volume loss at harvesting and $50 \%$ sawlog volume loss, in the form of wood residues, attributable to poor conversion efficiency (Chivuno 2010). Most sawmills use obsolete machines (Asamoah et al. 2020), which generate an increased amount of sawdust due to large kerfs (Ogunwusi 2014). Therefore, as demand increases in tandem with the number of sawmills, so does the amount of un-merchantable timber and wood residues. To optimize the utilization of sawlogs, starting January 2011, ZAFFICO reviewed timber allocation to between 35 and $100 \mathrm{~m}^{3}$ per month (ILO 2015; CCPC 2016). Such paltry allocation was regardless of variation in capacities of sawmills and sustained production for only 2 to 3 weeks (ILO 2015). A typical narrow bandsaw sawmill, e.g. LT40 woodmizer, producing $1.298 \mathrm{~m}^{3}$ per hour at $55 \%$ recovery rate, i.e. $10.4 \mathrm{~m}^{3}$ per day (Woodmizer n.d.) would require $415.5 \mathrm{~m}^{3}$ input volume per month, which is 8.4 to $24.1 \%$ of installed production capacity. The only respite is to purchase; unsold roundwood ensuing from sawmills that could not buy their allotments, residual trees remaining after harvesting and sales, and verifiable standing trees from private farms. In spite of the policy review providing for the allocation of timber to more sawmills, the unprecedented waste generation volume problem and the attendant disposal issues remain largely unresolved (Makumba 2002). Furthermore, the decision has adversely affected the performance of most sawn timber operations in the Copperbelt Province.

Although the reduction in raw material allocation is the most visible adverse limiting index, the other factors, e.g., a shortage of skilled labor, a lack of highly efficient machinery, and a lack of management skills contribute to the operational viability of sawmills (Bendery et al. 1994). There is therefore a need to overcome the limiting factors on sawmill operations in the Copperbelt of Zambia (Bomba et al. 2016). Limiting factors constrain the profit maximization of an enterprise (Chong 2008). Nevertheless, it is possible to identify the cause, which if lacking, will have an adverse impact on the profitability of the enterprise (Bendery et al. 1994).

Accurate and appropriate performance measurement is critical in small business research and the development of useful methodologies. The authors used a multidisciplinary approach, anchored in finance and wood processing technology, to understand the factors that affect the performance of small-to-medium scale sawmills. This is premised on the fact that performance measurement is an ongoing monitoring and progress reporting mechanism that helps rate the ability of a business to create jobs and wealth (Artley and Stroh 2001; Sandberg 2002).

Performance can be measured by profits before tax, capital turnover or profits, and revenue growth as well as delivery time, waiting time, and employee turnover (Komppula 2004; Chong 2008). Others posit profitability, solvency, risks ratios, and outsider perceptions, in addition to strategic, operating, and financing decisions as performance 
measurements (Weston and Copeland 1992; Watts 1993). Basu (2019) views liquidity and current ratio, solvency ratio and financial stability, profitability ratios and margins, and common efficiency ratios as the basic financial ratios for measuring the performance of a company. Financial analysts deploy profitability, growth, and valuation ratios with the sole purpose of tracking and comparatively judging the performance of a company (Corporate Finance Institute 2021). Deriving from the latter, the authors compared financial ratios of the sawmills that were allocated different timber volumes to judge their performance with respect to the industry benchmark.

The aforestated ratios are rarely used, as many small businesses are time constrained, and they lack requisite funding, knowledge, and strategic plans (Bergin 2009). However, the data collected from small-to-medium scale sawmills via survey techniques can be amenable to analysis via profitability ratios, i.e., margin ratios and return ratios. This would help resource starved sawmillers in Zambia and elsewhere to proffer strategies to sustain sawmilling and sawn timber supplies.

The aim of this study was to analyze the effects of non-financial factors, i.e., raw materials, transport, skilled labor, and sawn timber recovery, on profitability, i.e., gross profit margin, net profit margin, return on capital employed, working capital turnover, and return on investment, in order to optimize the performance of small-to-medium scale sawmills. The objectives of this study were to: (1) determine and benchmark financial performance indicators of small- to-medium scale sawmills against that of sawmills industry; (2) establish financial and non-financial limiting factors affecting the performance of small-to-medium scale sawmills; (3) establish current strategies implemented by small-to-medium scale sawmills to overcome the limiting factors affecting their sawmill businesses; and (4) propose measures for overcoming the limiting factors affecting the sawmill businesses.

\section{EXPERIMENTAL}

\section{Methods}

Sampling design

A population of 340 small-to-medium-scale sawmills registered with the Zambia National Association of Sawmillers (ZNAS) were stratified according to their monthly timber allocation volumes of $35,40,50,65$, and $100 \mathrm{~m}^{3}$. The ZNAS members in the Kalulushi, Kitwe, and Mufulira districts process pine and eucalypt timber grown on ZAFFICO plantations in the Copperbelt of Zambia.

A structured questionnaire was administered to a sub-sample of $6 \%$, comprising 4 small-scale sawmills selected randomly from each of the 5 strata under the framework of a descriptive research design. Additional information was obtained via follow-up interviews. The financial statements, i.e., an income statement and balance sheet, for the selected small-to-medium-scale sawmills were compiled from the survey data collected.

\section{Performance indicators data}

The financial statements from 7 large-scale sawmills operating in the region were obtained on a double-blind basis. Unlike most small and some medium-scale sawmills, large sawmills keep accounting records from which financial statements are prepared.

The financial statements of all the sawmill categories provided the data for calculating the industry benchmark and the performance ratings of sawmills. Performance 
was analyzed by profitability, i.e., margin ratios and return ratios. This was an efficient method to analyze the data collected. The profitability ratios (ZMK) were calculated from the financial statements, as shown in Eqs. 1 to 5,

$$
\begin{aligned}
& \text { Gross Profit Margin (GPM) }=\frac{\text { Gross profit }}{\text { Sales }} \\
& \text { Net Profit Margin (NPM) }=\frac{\text { Net profit }}{\text { Sales }} \\
& \text { Return on Investment (ROI) } \frac{\text { Net profit }}{\text { Costs of investment }} \\
& \text { Return on Capital Employed (ROCE) }=\frac{\text { Net profit }}{\text { Average capital }} \\
& \text { Working Capital Turnover (WCT) }=\frac{\text { Net sales }}{\text { Average working capital }}
\end{aligned}
$$

\section{Limiting factor's data}

Certain non-financial limiting factors affect the performance of sawmills and are amenable to conversion into a monetary value. These values, in their natural logarithm form, were analyzed via a linearized Cobb-Douglas model in a Statistical Package for the Social Sciences (SPSS) environment to establish their impacts and predict the performance of small-to-medium scale sawmills in the Copperbelt Province of Zambia, as shown in Eq. 6 ,

$$
Y=\beta_{0} X_{1}^{\beta_{1}} X_{2}^{\beta_{2}} X_{3}^{\beta_{3}} X_{4}^{\beta_{4}} \in
$$

where $\mathrm{Y}$ is the net profit margin (ZMK), $X$ is the explanatory variable $(\mathrm{ZMK}), \beta_{0}$ is the constant $(\mathrm{ZMK}), \beta_{1}$ is the raw material $(\mathrm{ZMK}), \beta_{2}$ is the transport $(\mathrm{ZMK}), \beta_{3}$ is the skilled labor (ZMK), and $\beta_{4}$ is the sawn timber recovery (\%). This expression becomes Eq. 7,

$$
\ln Y=\ln \beta_{0}+\beta_{1} \ln X_{1}+\beta_{2} \ln X_{2}+\beta_{3} \ln X_{3}+\beta_{4} \ln X_{4}+\ln \epsilon,
$$

when linearized and the factor variables are in natural logarithmic form.

\section{RESULTS}

The results of this work showed that sawmills allotted different timber volumes $\left(\mathrm{m}^{3}\right)$ performed distinctively against the industrial bench marks (Table 1). It was further found that both financial and non-financial factors adversely affect the operations of the sawmills in Zambia.

\section{Industry Bench Marked Performance of Small-to-Medium Scale Sawmills}

Eighty-five percent of the subjects responded, and Table 1 summarizes the performance measures for the small-to-medium-scale sawmills benchmarked against the sawmills industry.

All the ratios, except for the gross profit margin ratio, for the sawmills allocated 35 to $50 \mathrm{~m}^{3}$ of timber were below the benchmark (Table 1). These profitability ratios measure the ability of a business to generate income relative to revenue, balance sheet assets, operating costs, and equity (Corporate Finance Institute 2021). The ratios are a coalescence of margins, i.e., the ability to translate sales into profits, and returns or the ability to measure the overall efficiency of the firm in terms of generating returns for its shareholders. 
Table 1. Financial Performance of Small-to Medium-scale Enterprises BenchMarked with the Industry Average

\begin{tabular}{|l|l|l|l|l|l|l|l|}
\hline Timber Allocation Volume $\left.\mathbf{( m}^{\mathbf{3}}\right)$ & $\mathbf{> 1 0 0}$ & $\mathbf{1 0 0}$ & $\mathbf{6 5}$ & $\mathbf{5 0}$ & $\mathbf{4 0}$ & $\mathbf{3 5}$ & Benchmark \\
\hline Gross profit margin (GPM) (\%) & 51 & 40 & 30 & 45 & 53 & 25 & 40.7 \\
\hline Net profit margin (NPM) $\%)$ & 11 & 9 & 6 & 3 & 2 & 1 & 5.3 \\
\hline Return on capital employed (ROCE) (\%) & 14 & 20 & 9 & 4 & 2 & 1 & 8.3 \\
\hline Working capital turnover (WCT) $\left({ }^{*}\right.$ times) & $0.3^{*}$ & $2.3^{*}$ & $1.9^{*}$ & $0.1^{*}$ & $0.5^{*}$ & $0.2^{*}$ & 0.9 \\
\hline Return on investment (ROI) (\%) & 10 & 12 & 10 & 1 & 6 & 4 & 7.2 \\
\hline
\end{tabular}

\section{Financial Factors Limiting the Performance of Sawmills}

Two main financial factors limiting the performance of small-to-medium scale sawmills in Zambia were found. These are limited access to finance and high operating costs.

\section{Access to finance}

Sawmills need funds to buy modern equipment and obtain working capital. To obtain the necessary funds, small-to-medium scale sawmills have to compete in the financial market with large-scale sawmills. Almost $94 \%$ of the small-to-medium scale sawmills identified difficulty in securing bank loans. Most of them do not have property to use as collateral, following the requirements of most financial lending institutions. Thus, lack of collateral, high lending rates, and low profit margins make the situation challenging for the small-to-medium scale sawmillers to secure funds to invest in working capital.

\section{Operating costs}

Fifty-three percent of the sawmills expressed an inability to effectively control costs. Approximately 59\% of operating costs of a sawmill were in the $50 \%$ to $70 \%$ range, while $23 \%$ and $18 \%$ of sawmills had an $18 \%$ and $23 \%$ operating cost proportion, respectively. The sawmills attributed the high operating costs to various factors such as transport, labor and rental costs.

\section{Non-financial Limiting Factors Affecting the Performance of Sawmills}

Table 2 summarizes the non-financial limiting factors that were perceived to affect the performance of sawmills in the Copperbelt Province of Zambia. The survey revealed that $100 \%$ of the respondents considered shortages of raw materials and $80 \%$ of them considered usage of old machinery as the topmost constraints affecting the performance of sawmills. Additionally, the survey revealed that $30 \%$ of the workers in the small-tomedium sawmill industry were skilled and transport costs were $25 \%$ of the sales.

Table 2. Percentages of Small- to Medium-scale Sawmills that Considered the Listed Non-financial Limiting Factors as Affecting the Performance of Their Operations

\begin{tabular}{|l|l|}
\hline Limiting Factors & (\%) \\
\hline Shortage of timber & 100 \\
\hline Inadequate skilled staff & 71 \\
\hline Transportation costs & 53 \\
\hline Use of old machinery & 80 \\
\hline
\end{tabular}


Four limiting factors (shown in Table 2), amenable to quantification, were modelled to ascertain their influence on sawmill performance. These factors were as follows: raw material $\left(\beta_{1}\right)$, skilled labor $\left(\beta_{3}\right)$, transport $\left(\beta_{2}\right)$, and use of old machinery. The monetary value of the other two limiting factors, i.e., a problem in accessing loans and the inability to control costs, could not be ascertained, as they were unamenable to financial quantification. Sawn timber recovery $\left(\beta_{4}\right)$ was employed as a proxy for old machinery, predominantly circular saw technology.

Summary statistics showed a monotonic relationship, referred to as a learning curve, between the explanatory variables and the response variable (Jerome 2009). This curve was modelled via a linearized Cobb-Douglas function on the log-log transformed data (using Eq. 7, as shown in Fig. 1). The overall model is highly significant at the $1 \%$ significance level $(F$-value $=292.81, p$-value $=0.000)$ with $\mathrm{R}^{2}=0.994$, which indicated that $99.4 \%$ of the total variation in the $\mathrm{Y}$-variable (profit) was explained by the four explanatory variables, i.e., $\beta_{1}$ through $\beta_{4}$, in the model. The t-tests indicated that only $\beta_{1}$ $(t$-value $=6.667, p$-value $=0.000)$ and $\beta_{4}(t$-value $=-3.894, p$-value $=0.006)$ significantly contributed to the estimation and prediction of $\mathrm{Y}-$ (as shown in Table 3 ).

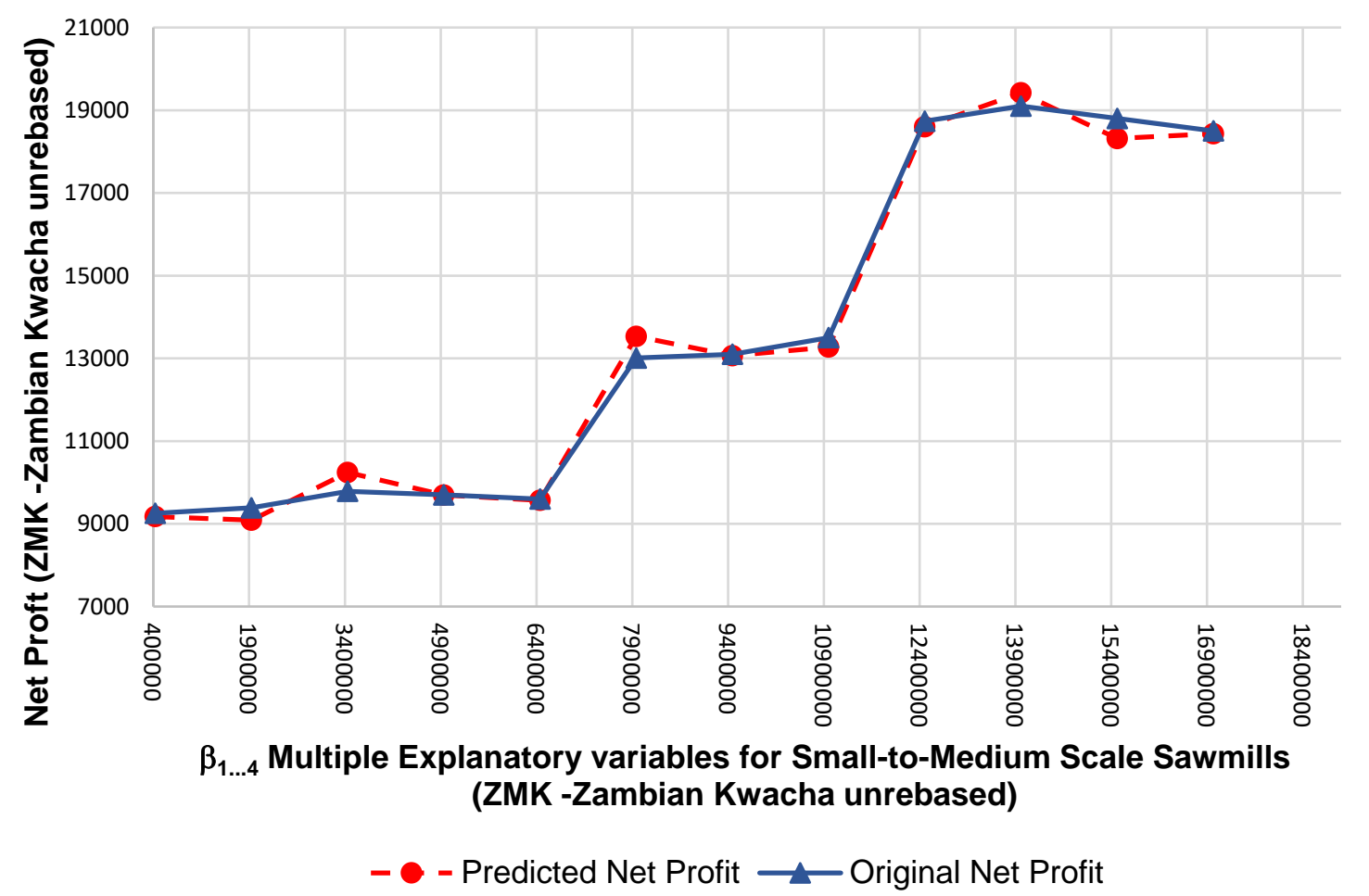

Fig. 1. Capability of the Cobb-Douglas model to predict net profit relative to the variation in nonfinancial limiting factors $(Z M K)$, i.e., the value of the timber input volume $\left(\beta_{1}\right)$, skilled labor cost $\left(\beta_{3}\right)$, transportation costs $\left(\beta_{2}\right)$, and value of the sawn timber produced $\left(\beta_{4}\right)$

The independent variables were highly intercorrelated, with the coefficients of correlation among the four independent variables being almost 1 (as shown in Table 3). This indicated a severe problem of multicollinearity, as confirmed by a large variance inflation factor (VIF) values $\left(\beta_{1}=77.35, \beta_{2}=33.35, \beta_{3}=47.45\right.$, and $\left.\beta_{4}=11.73\right)$. This problem is negligible when the VIF values are small, but when these values are large, i.e., greater than 10, then the problem of multicollinearity is severe. The maximum VIF value of 77.35 indicated a severe problem of multicollinearity and that the estimated regression 
coefficients were affected in the sense that they were inefficient, imprecise, and had large variances. Additionally, the common interpretation of regression coefficients, i.e., measuring the change in the expected value of the dependent variable when the corresponding independent variables are held constant, was not applicable.

Table 3. SPSS Outputs from Running a Linearized Cobb-Douglas Function on the Log-Log Transformed Data Indicating the Effects of Non-Financial Factors on the Profit of Small-to-Medium Scale Sawmills

\begin{tabular}{|c|c|c|c|c|c|c|}
\hline \multirow{2}{*}{ Model } & \multicolumn{2}{|c|}{$\begin{array}{c}\text { Unstandardized } \\
\text { Coefficients }\end{array}$} & \multirow{2}{*}{$\mathrm{t}$} & \multirow{2}{*}{ Sig. } & \multicolumn{2}{c|}{ Collinearity Statistics } \\
\cline { 2 - 3 } & $\beta$ & Std. Error & & & Tolerance & VIF \\
\hline (Constant) & -4.654 & 1.183 & -3.935 & .006 & & \\
\hline$\beta 1$ & 2.111 & .317 & 6.667 & .000 & .013 & 77.357 \\
\hline$\beta 2$ & -.376 & .223 & -1.686 & .136 & .030 & 33.351 \\
\hline$\beta 3$ & -.078 & .225 & -.345 & .740 & .021 & 47.451 \\
\hline$\beta 4$ & -.312 & .080 & -3.894 & .006 & .085 & 11.737 \\
\hline
\end{tabular}

The derived Cobb-Douglas model could be used for predicting the $Y$-values quite accurately (Fig. 1) by varying the raw material input and sawn timber conversion efficiency in a direct relationship. This indicates that sawmills that had been allocated a higher volume of raw materials, i.e., greater or equal to $65 \mathrm{~m}^{3}$ and also had attained a higher sawn timber recovery, were successful or profitable as their NPM increased in tandem with ROI (Table 1). This attested that these sawmills generated higher profits to sustain their business operations because they were sufficiently resourced to efficiently manage their investment in assets.

\section{Current Strategies Adopted by Sawmills to Improve Their Performance}

In response to the existing constraints, some of the sawmills adopted a range of strategies to sustain their business operations and achieve higher profit margins. The strategies found in this study include; Multiple raw material supplier sourcing, Roundwood transportation, Modernization of wood processing equipment, Cost reduction, and Value addition. Lähtinen and Toppinen (2008), Korhonen and Niemelä (2005), Lähtinen and Toppinen (2008), and Korhonen and Niemelä (2005) observed similar strategies such as; value added production, and utilization of wood residues.

\section{Multiple raw material supplier sourcing}

The survey indicated that $100 \%$ of the respondents regarded the issue of raw materials as a daunting problem (Table 2). Ogechukwu (2006) and Chivuno (2010) also indicated that timber raw material is a major factor leading to frequent production shortfall and stoppages in the sawmilling industry. There is uncertainty in the timber availability from ZAFFICO based on the age structure of the plantation timber species (Chivuno 2010).

Some sawmills are therefore importing wood products, especially sawn softwood timber from Malawi and treated wood poles from South Africa and Zimbabwe (Lukumbuzya and Sianga 2017) to augment the dwindling raw material from ZAFFICO.

It was observed that other sawmills fail to pay for the timber volumes they have been allocated by ZAFFICO. Consequently, this unsold timber is availed for purchase by sawmills with a deficit in raw material supply. 
The survey also revealed that ZAFFICO has eucalypt trees, in the order of 10,382 hectares, that can be accessed by sawmills to augment dwindling pine allocations. Thus, sawmills can buy eucalypt trees to produce the needed timber and other products, but just a few sawmills have taken up this alternative raw material source.

\section{Labor skills}

Many of the workers acquired their on-the-job skills that were normally below the expected competency levels. Some sawmills resolved this by shifting from a full permanent staff complement to engaging workers on contract and downsizing the labor force.

\section{Roundwood transportation}

The survey showed that transport costs were $25 \%$ of the sales. A sawmill that could procure logs nearby had an advantage over sawmills that had to haul timber over much longer distances. Transport plays a role in productivity and the availability of resources (Harouff et al. 2006). As time can roughly be used as a proxy for cost, the longer the distance the truck had to travel, the higher the variable costs in labor and fuel. As a cost cutting measure, some sawmills had acquired their own logging vehicles, whilst others were in the process of doing so. To reduce the cost further, some sawmills substituted hired logging equipment by acquiring chain saws.

\section{Modernization of processing machine technology}

Eighty-eight percent of the sawmills were using circular saw technology, while $6 \%$ used push-bench and 6\% used bandsaw technology. As recovery is, to some extent, a function of processing technology, the data elicited showed values of $21 \%, 32 \%, 36 \%$, and $51 \%$ across the sawmills involved in the study. The low recovery of $21 \%$ to $36 \%$ observed could be attributed to circular saw and push-bench technologies. Whilst conventional circular saw machines cut precisely with minimal variation, yielding $36 \%$ recovery, their large kerf accentuates production of wood sawdust residues. This problem was at a larger order of magnitude at sawmills where push-benches were being used. A push-bench is a rudimentary home-made machine, which lacks sturdy sawlog set-works and feed devices to ensure vibration free all-round sawing accuracy. The lowest recovery amount (approximately 21\%) was ascribed to this machine technology.

The majority $(53 \%)$ of sawmills had taken measures to increase recovery by modernizing their wood processing machinery. A few (12\%) sawmills had taken the value addition route, while approximately a third (35\%) had not taken any action at all.

\section{Value addition}

Most sawmills are making various products in addition to sawn timber including brandering, exotic wood charcoal, fruit crates and pallets from slabs. This converts wood residues into saleable merchandise. The value-addition of sawn timber has been proposed primarily to achieve sound financial performance of production entities. Lähtinen and Toppinen (2008) found that the value created affected longer-term financial performance and future turnover growth while the more immediate benefits were reflected by monitoring cost-efficiency. 


\section{DISCUSSION}

\section{Performance of Small-to-Medium Scale Sawmills}

Table 1 shows that all the ratios for the sawmills allocated $35 \mathrm{~m}^{3}$ of timber were below the benchmark. The GPM, i.e., the percentage of each Zambia kwacha of revenue returned, was high. However, the higher the percentage, the more efficient management was in generating profit for every kwacha of cost involved. Even though the GPM margin seemed ranging from $25 \%$ to $53 \%$, it was still below the industry benchmark where timber allocation was $65 \mathrm{~m}^{3}$ and $35 \mathrm{~m}^{3}$. This indicated that operational costs were high, i.e., there were ineffective controls of inventory and manufacturing costs or trading performance. However, other sawmills were breaking even with the GPM of 40\% to 53\%, which was above the industry benchmark. Operating costs comprise of fixed costs and variable costs. The latter varied in unison with business activity calibrated as production or sales volume $\left(\mathrm{m}^{3}\right)$, or hours worked. While fixed costs, e.g., rent, are stagnant, variable costs, e.g., raw materials, fluctuate with outputs. It can be deduced that with a volume allocation greater than $40 \mathrm{~m}^{3}$, the fixed and variable costs were at par such that additional timber acquisition could thereafter turn a profit.

The NPM, i.e., the amount of each Zambia kwacha collected by a sawmill as revenue that translates to profit, for all sawmills, was much lower than the benchmark for sawmills allocated up to $50 \mathrm{~m}^{3}$ of timber. This might be attributed to higher average overheads for the level of sales generated which included administrative and selling expenses.

A stable ROCE can be a sign of excellency, as it shows consistent good usage of resources. With the exception of sawmills allocated greater than $65 \mathrm{~m}^{3}$ of timber, the ROCE for the other sawmills was low. As the ROCE measures the overall performance of a company, the results indicated that the sawmills allocated $35 \mathrm{~m}^{3}$ to $50 \mathrm{~m}^{3}$ of timber were underutilizing their assets, i.e., capital employed. If they were to borrow capital, they might face difficulties in paying it back. However, astute sawmills could improve their profit margin, by reducing operational costs, to help increase the ROCE. Thus, the decision taken by some sawmills to consider employing workers on part-time basis was prudent so as to reduce on the labor costs resulting from idle time. A reduction in operation costs would enable most sawmillers to increase their ROCE, which would help them buy assets to enable them access loan facilities.

Return on investment is the barometer that investors often use based on the historical average return of the S\&P 500 after adjusting for inflation. A good ROI is generally considered to be approximately $7 \%$ per year. The ROI, i.e., the amount of return on the cost of a particular investment, for the sawmills aggregated into low $\left(35 \mathrm{~m}^{3}\right.$ to 50 $\left.\mathrm{m}^{3}\right)$ and high $\left(65 \mathrm{~m}^{3}\right.$ to $\left.100 \mathrm{~m}^{3}\right)$ timber allocations. This indicated that sawmills allocated greater than $65 \mathrm{~m}^{3}$ of timber were sufficiently resourced to efficiently manage investment in assets and successfully used them to generate profit. However, given the same net profit after taxes, since there were differences in the age and condition of fixed assets, which tend to complicate interpretation of this ratio, a business with highly depreciated fixed assets will have higher ROI than with new fixed assets. However, this technicality was negligible because the ROI ratios increased in tandem with the volume of timber allocated to a sawmill. 


\section{Current Strategies}

The conducted survey clearly showed that running a sawmilling business is challenging in Zambia. The majority of sawmills attested that the timber volume allocation of ZAFFICO has been declining over the years, which is negatively affecting their business performance. The annual allowable cut volume of a sole roundwood supplier $\left(200,000 \mathrm{~m}^{3}\right)$ has been insufficient to meet demand (Ng'andwe et al. 2017). However, between 2006 and 2014, ZAFFICO started more vigorous replanting in its plantations blocks in the Copperbelt Province and expanding its plantation base by establishing Kawambwa (in 2014 and 2015) and Shiwang'andu (in 2015 and 2016) plantation groups in the Luapula and Muchinga Provinces of Zambia, respectively (ZAFFICO n.d.). These endeavors are yet to bear fruit, as the number of sawmills has increased to more than 1000 in the 2020 financial year in tandem with increased economic activities spurred by population growth (ZAFFICO 2020).

As an immediate measure, ZAFFICO has made available eucalypts tree species to augment the dwindling pine allocations. There is no limit on harvesting eucalypt timber, which comprises of 1.62 million $\mathrm{m}^{3}$ in ZAFFICO plantations in the Copperbelt Province (Ng'andwe et al. 2017). However, the material is not fully tapped, as just a few sawmills have the expertise to process it (ZAFFICO n.d.). The reason put forward by sawmills for not purchasing eucalypt timber is the skill deficiency in processing the refractory Eucalyptus grandis and E. cloeziana. Refractory timbers are characterized by growth stress and are also slow and difficult to dry, making them liable to cracking, splitting, and warping. Excessive saw binding and splitting during processing leads to low sawn timber recovery of $25 \%$ and an array of distortions, checking, and splitting associated with a high drying degradation of 24\% (Ncube and Mulenga 2013). A high number of sawmills do not have a cohort of machine operators and timber drying personal with the know-how to manipulate the material and to control process variables. These competencies are key to realizing acceptable conversion and drying efficiencies.

To reduce on operation expenses, most sawmillers are buying their own trucks. Unfortunately, some of the public and plantation roads in Zambia are in poor condition, which increases the wear and tear on trucks, and frequent breakdown of logging vehicles is experienced. This increases the operating costs of the sawmills. While mobile sawmilling at the felling site is a viable strategy to reduce log haulage costs, this is not permissible within ZAFFICO plantation blocks.

Further reduction of operating costs through modernization of machinery is essential to minimize wastage of resources, but the sawmilling industry in the Copperbelt of Zambia has been slow to invest, which is inadvertently affecting their performance (Blackwell and Stewart 2003). Currently, a small number (6\%) of sawmills have migrated to narrow bandsaw technology, which has realized better recovery (approximately $50 \%$ ). However, the manual set-works and feed mechanisms of the bandsaw technology common amongst Zambian sawmills is incumbent on the ability of the operator to match the log form, cutting pattern, and sawing parameters to a conversion procedure that optimizes the sawn timber output volume and quality. Frogner (2002) recognizes that labor skills limit the production and quality of products and has a noticeable effect on the performance, which subsequently reduces earnings. Only a highly skilled operator would have the capacity to unlock the full competitive edge of narrow bandsaw technology. The largely manual wood processing bandsaw technology still depends upon operator skills to optimize output; therefore, the full benefit of equipment moderation should be done in tandem with 
upgrading sawmill personal skills in order to improve the performance of the sawmill and the utilization of scarce exotic plantation timbers resources.

The low sawn timber recovery attributed to inappropriate saw technology is characterized by an increased input volume (Chivuno 2010). This is an artefact created to make up for the purchased raw material that was lost as residues during harvesting and sawmilling (Ogechukwu 2006).

It is incumbent on the sawmills that cannot modernize and upgrade their labor skills to collaborate with bioenergy companies so that their wood residues can be offloaded at a fee to be used as bioenergy feedstock. Shane et al. (2016) pegged residues from industrial roundwood logging at 1.3 million $\mathrm{m}^{3}$ based on a $60 \%$ efficiency and $134750 \mathrm{~m}^{3}$ from sawmilling based on a 55\% recovery. Sawmillers can realize revenue by synergizing their operations with bioenergy companies by utilizing the biomass residues energy potential at the logging $\left(6,360,000 \mathrm{GJ}^{-1}\right)$ and processing $\left(1,078,000 \mathrm{GJ}^{-1}\right)$ phases of the industrial wood value chain.

Many of the workers were self-trained, and so their skills levels were normally below standard. This problem of insufficient sawmilling skills primarily contributed to the inability of most sawmills to maximize recovery and control operation costs. The sawmills utilizing workers without the requisite skills incurred an increase in operation costs, experienced a decrease in turnover, as well as faced irregular and unreliable workmanship.

\section{Proposed Measures for Overcoming the Limiting Factors Affecting the Sawmill Businesses}

From an analysis of the results, it is clear that the current implemented strategies have not improved the situation, as the recovery rate and profits are still below the industry average while the amount of waste is still high. Therefore, there is a need for the industry to look for alternative strategies in order to reduce waste and maximize profit. Strategic purchases of unregulated raw material in higher volumes, controlled operational costs, and efficient retrieval of the highest potential grades of timber over a calculated operating period ensure profitability. Other measures may include the following: the development of credit guarantee schemes, provision of tax incentives, collaboration on innovation, and establishment of a timber auction floor.

\section{Development of credit guarantee schemes}

As earlier alluded to, small- and medium-scale sawmills have severe difficulties raising money primarily because of the high default risk and lack of collateral. This problem can be solved by developing credit guarantee schemes (CGS) by either the government or sawmill associations. A CGS provides a third-party credit risk mitigation to lenders through the absorption of a portion of the losses of the lender on the loans made to small-to-medium enterprises (SMEs) in case of default, typically in return for a fee. A CGS consists of three parties - a borrower, a lender, and a guarantor. The borrower is often an SME seeking debt capital. This borrower typically approaches a private financial institution (bank) for a business loan (lender). The guarantor facilitates access to debt capital by providing lenders with the comfort of a guarantee for a substantial portion of the debt.

In the Zambian situation, the sawmills can negotiate with the Zambian Government to be the guarantor, which helps facilitate acquisition of the loans. Currently, there are a number of sawmill associations, e.g., the Zambia National Association of Sawmillers, and the Timber Producers Association of Zambia (TPAZ). The associations can also play the 
role of guarantor to help registered sawmills access loans. However, all registered sawmills would need to pay registration fees to the association, which could be categorized depending on the size of the sawmill. The association would then determine the maximum amount that they could facilitate depending on the size of the sawmill and the registration fees paid to the association.

The sawmills should negotiate through the associations with the government for tax relief considering the size of the business and the difficulties the industry is going through.

\section{Collaboration}

New innovations and technologies are typically too expensive for individual sawmills to be able to afford them. Therefore, small- and medium-scale sawmills could collaborate to pay for new technologies that can benefit all partners.

\section{Improved waste management strategies}

It has been proposed to use wood waste in the production of particleboard, chipboard, and plywood (Asamoah et al. 2020). However, though these products can be manufactured from the waste, small and medium scale sawmillers in the country lack facilities for the utilization of waste (Ogunwusi 2014). Thus, as a solution to limited facilities, small and medium scale sawmillers should work together by forming associations and acquire the needed equipment. It is further proposed that small and medium scale sawmillers should work closely with large sawmills that already have equipment and are currently producing the various products from wood waste. These large sawmills can buy the waste from the small-scale sawmillers at a low cost. The sawmilling industry could also collaborate with other companies in different sectors, e.g., the bioenergy sector, where waste from the sawmills can be used as a raw material by the bioenergy industry.

\section{Utilization of lesser-used indigenous tree species}

To curb the problem of the shortage of raw material, sawmillers should be encouraged to use the available lesser-used wood species (Sekeli and Phiri 2002). However, more research needs to be done on these species to better understand their properties for timber producers to buy into the idea. Currently, the properties of these lesser-utilized tree species are not well understood (Ogunwusi 2014) in Zambia.

\section{Establishment of Timber Auction floor}

Currently, Zambia has no well-established system of selling timber and exporting it. For small and medium scale sawmillers, exporting is challenging due to the high cost and logistical challenges. It is therefore proposed that sawmillers, through their associations, lobby the government to establish a Timber Auction Floor. Through auction floor, the sector can attract an international market and timber can be sold at a competitive price.

\section{CONCLUSIONS}

1. The gross profit margin for most sawmill categories was below the average for industry in general, which was indicative of highly elevated operating costs. Overhead costs increased as calibrated by the decrease in net profit margin. Furthermore, the decrease 
in return on capital employed was symptomatic of the underutilization of capital employed, which in turn points to the inability of the sawmills to service loans. Development of credit guarantee schemes and provisioning tax incentives can give sawmills a respite.

2. The failure of sawmills allocated $35 \mathrm{~m}^{3}$ and $50 \mathrm{~m}^{3}$ of timber to generate revenue for their sustainability, as marked by working capital turnover deficit, could be addressed through effective utilization of short-term debts/liabilities. Interestingly, a higher timber allocation $\left(65 \mathrm{~m}^{3}\right.$ and $\left.100 \mathrm{~m}^{3}\right)$ coincided with a higher return on investment, which is characteristic of a business that has sufficient resources to manage its investment. The sawmills that are profitable/successful are the ones which are allocated more timber, as they are breaking even by balancing costs and benefits. This observation was confirmed by the Cobb-Douglas model in support of the overwhelming concern by sawmills that inadequate timber allocations are adversely affecting performance and squeezing them out of business.

3. Several sawmills had adopted a range of strategies to counter the existing constraints. These strategies included value added production, product differentiation marketing, outsourcing timber, contract labor employment, the purchasing of their own equipment, and sawmilling machinery modernization.

\section{ACKNOWLEDGMENTS}

The authors are grateful for the support rendered by Copperbelt University and the timber industries in the Copperbelt Province of Zambia.

\section{REFERENCES CITED}

Artley, W., and Stroh, S. (2001). Establishing an Integrated Performance Measurement, Oak Ridge Institute for Science and Education, Oak Ridge, TN.

Asamoah, O., Kuittinen, S., Abrefa Danquah, J., Quartey, E. T., Bamwesigye, D., Mario Boateng, C., and Pappinen, A. (2020). "Assessing wood waste by timber industry as a contributing factor to deforestation in Ghana," Forests 11(9), 939. MDPI AG. Retrieved from, (http://dx.doi.org/10.3390/f11090939), Accessed 6 August 2021

Basu, C. (2019). "Four basic types of financial ratios used to measure a company's performance," (https://smallbusiness.chron.com/four-basic-types-financial-ratiosused-measure-companys-performance-25299.html), Accessed 12 March 2021.

Bendery, M., Hussey, R. and West, C. (1994). Accounting and Finance for Business Students, DP Publications, London, United Kingdom.

Bergin, S. (2009). Benchmarking Small Business Performance: Barriers, Master's Thesis, Victoria University, Melbourne, Australia.

Blackwell, P. and Stewart, M. (2003) Using Portable Sawmills to Produce High Value Timber From Farm Trees in the Semi-Arid Zone (Project No. PN99.2001), Rural Industries Research and Development Corporation, Melbourne, Australia.

Bomba, J., Böhm, P., Sedvika, P., Freiss, F., and Oralkova, R. (2016). "Influence of selected factors on the sawing capacity of sawmills in the Czech Republic," Scientia Agriculturae Bohemica 47(4), 174-180. DOI: 10.1515/sab-2016-0025 
Chivuno, N. (2010). Assessment of the Constraints to the Development of Forest and Wood Products Industry in Zambia, Consultancy Report, Embassy of Finland, Lusaka, Zambia.

Chong, H. G. (2008). "Measuring performance of small-and-medium sized enterprises," Journal of Business and Public Affairs 2(1), 1-11.

Corporate Finance Institute (2021). "Complete list and guide to all financial ratios," (https://corporatefinanceinstitute.com/resources/knowledge/finance/financial-ratios/), Accessed 23 February 2021.

Competition and Consumer Protection Commission (CCPC) (2016). Barriers to Entry, exclusionary strategies, regulation and inclusive growth in the Forestry Sector in Zambia, 2nd Annual Competition and Economic Regulation Week, $8^{\text {th }}$ to $12^{\text {th }}$ March 2016, Avani Hotel, Livingstone, Zambia.

Frogner, M. (2002). "Labour market trends: Skills shortage,” Office for National Statistics, Labour Market Division (www.dti.ac.uk.), Accessed 11 January 2010.

Harouff, S. E., Grushecky S. T., and Spong, B. D. (2006). "West Virginia forest industry transportation network analysis using GIS," in: Proceedings of the $16^{\text {th }}$ Central Hardwoods Forest Conference, April 8-9, West Lafayette, IN, pp. 257-264.

Internal Labour Organization (ILO) (2015). Practical Options for the Extension Social Protection Coverage in Zambia, Casual Saw Mill Workers Report, ILO Lusaka Office, Zambia.

Komppula, R. (2004). Success Factors in Small and Micro Businesses - A Study of Three Branches of Industry in North Karelia, University of Joensuu, Joensuu, Finland.

Korhonen, S., and Niemelä, J. S. (2005). "A conceptual analysis of capabilities: Identifying and classifying the sources of competitive advantage in the wood industry," The Finnish Journal of Business Economics 54(1), 11-47.

Lähtinen, K. and Toppinen, A. (2008). "Financial performance in Finnish large- and medium-sized sawmills: The effects of value-added creation and cost-efficiency seeking," Journal of Forest Economics 14(4), 289-305. DOI: 10.1016/j.jfe.2008.02.001

Lukumbuzya, K. and Sianga, C. (2017). Overview of the Timber Trade in East and Southern Africa: National Perspectives and Regional Trade Linkages, TRAFFIC, Cambridge, United Kingdom, pp. 1-79.

Makumba, I. N. (2002). "Tropical secondary forest management in Africa: Reality and perspectives Zambia country paper," in: Proceedings of the Workshop on Tropical Secondary Forest Management in Africa, December 9-13, Nairobi, Kenya.

Ng'andwe, P., Chungu, D., Ratnasingam, J., Ramananantoandro, T., Donfack, P., and J. Mwitwa J. (2017). "Forestry industry development in Zambia: An opportunity for public private partnership for small and medium enterprises," International Forestry Review 19(4), 467-477. DOI: 10.1505/1465548822272374

Ncube, E., and Mulenga, C. (2013). "Modifying a drying protocol to control Eucalyptus grandis rough sawn timber degrade: The case of Kafubu sawmill," Zambia Journal of Chemical Engineering 2(1), 64-71.

Ogechukwu, A. (2006). "The role of small scale industry in national development in Nigeria," Universal Journal of Management and Social Sciences 1(1), 23-41.

Ogunwusi, A. (2014). "Wood waste generation in the forest industry in Nigeria and prospects for its industrial utilization," Civil and Environmental Research 6, 62-69.

Sandberg, K. (2002). "An exploratory study of women in micro enterprise: Genderrelated differences," Journal of Small Business and Enterprise Development 10(4), 
408-417. DOI: 10.1108/14626000310504710

Sekeli, P. M., and Phiri, M. (2002). State of Forest and Tree Genetic Resources in Zambia. Prepared for the Second Regional Training Workshop on Forest Genetic Resources for Eastern and Southern African Countries 6-10 December 1999, Nairobi, Kenya; and updated for the SADC Regional Workshop on forest and tree genetic resources, 5-9 June 2000, Arusha, Tanzania. Forest Genetic Resources Working Papers, Working Paper FGR/31E. Forest Resources Development Service, Forest Resources Division. FAO, Rome, Italy (unpublished), (http://www.fao.org/3/AC455E/ac455e00.htm\#Contents) Accessed 5 August 2021.

Siampale, A., Phin, M., Musonda, B., and Nrirenda, I. (2020). Natural Capital Accounts for Forests 2010 to 2015, Government of the Republic of Zambia, Ministry of Lands and Natural Resources and Ministry of National Development Planning, Lusaka, Zambia.

Watts, J. (1993). Accounting in the Business Environment, Pitman Publishing, London, United Kingdom.

Weston, J. F., and Copeland, T. E. (1992). Managerial Finance, $9^{\text {th }}$ Edition, Dryden Press, Fort Worth, TX.

Woodmizer (n.d.) "Woodmizer," (https://woodmizer.com/us/LT40-Hydraulic-PortableSawmill, Accessed 21 September 2021)

Zambia Forestry Action Plan (ZFAP) (1998). Zambia Forestry Action Plan Final Report (Vol. 1), Forestry Department, Lusaka, Zambia.

Zambia Forestry and Forest Industries Corporation Limited (2004). Five Year Forestry Management Plan (2004-2008), Ndola, Zambia.

Zambia Forestry and Forest Industries Corporation Limited (2008). Plantation Management Plan 2008-2013, Ndola, Zambia.

Zambia Forestry and Forest Industries Corporation Limited (2020). Know Your Customers Report 2020, Ndola, Zambia.

Zambia Forestry and Forest Industries Corporation PLC (n.d.). "Shiwangandu," (http://www.zaffico.co.zm/?page_id=476), Accessed 3 February 2021).

Article submitted: March 24, 2021; Peer review completed: June 7, 2021; Revised version received: October 25, 2021; Accepted: October 26, 2021; Published: November 19, 2021.

DOI: 10.15376/biores.17.1.369-383 